\title{
PENGENDALIAN PERSEDIAAN TABUNG GAS LPG UNTUK MEMINIMASI TOTAL BIAYA PERSEDIAAN (Studi kasus di PT Wina Wira Usaha Jaya, Yogyakarta)
}

\author{
Gunawan Madyono Putro dan Rizky Fawzi Eka Saputro \\ Program Studi Teknik Industri, Jurusan Teknik Industri, Fakultas Teknik Industri \\ Universitas pembangunan Nasional "Veteran" Yogyakarta \\ Jl. Babarsari 2 Tambakbayan, Yogyakarta, 55281 \\ Telp. (0274) 485363 Fak : (0274) 486256 email : jur_tiupn@telkom.net
}

\begin{abstract}
ABSTRAK
Penelitian dilakukan pada sistem persediaan tabung gas LPG di PT. Wina Wira Usaha Jaya, Yogyakarta. Saat ini perusahaan tersebut belum memiliki jadwal pasti untuk penebusan tabung gas dan hanya melakukan penebusan tabung LPG perhari tergantung pada tabung kosong yang tersedia. Terbatasnya penebusan tabung LPG serta permintaan konsumen yang tidak pasti sering menyebabkan kurangnya persediaan tabung $L P G$ di gudang. Kekurangan dari permintaan baru bisa dipenuhi pada periode pemesanan berikutnya yang mengakibatkan beberapa konsumen beralih kepada agen lain untuk memenuhi kebutuhannya. Adapun tujuan dari penelitian ini adalah untuk menentukan periode pemesanan serta jumlah pemesanan tabung gas LPG supaya dapat memenuhi permintaan konsumen.

Metode yang digunakan dalam penelitian ini adalah dengan menggunakan model periodic review $(P)$. Metode periodic review ini digunakan untuk menentukan waktu periode pemesanan dan menentukan jumlah maksimal persediaan di gudang. Hasil analasis perhitungan biaya persediaan dengan menggunakan metode model periodic review ini akan dibandingkan dengan biaya persediaan yang dilakukan oleh perusahaan saat ini.

Berdasarkan dari hasil pengolahan data dapat disimpulkan bahwa dengan menggunakan model periodic review didapatkan biaya persediaan yang lebih minimal. . Adapun system persediaan yang dilakukan adalah dengan cara sebagai berikut: periode pemesanan untuk tabung gas $12 \mathrm{~kg}$ adalah 0,0022 tahun (1 hari), dan periode pemesanan untuk tabung gas $50 \mathrm{~kg}$ adalah 0,0192 tahun (7 hari). Sedangkan jumlah persediaan maksimal untuk tabung gas ukuran $12 \mathrm{~kg}$ adalah 817 tabung. dan untuk $50 \mathrm{~kg}$ adalah 79 tabung. Dengan menggunakan system persediaan periodic review maka biaya persediaan berkurang 3,24\%. dari kebijakan perusahaan sebelumnya.
\end{abstract}

Kata Kunci: Persediaan, biaya, Periodic Review model

\section{PENDAHULUAN}

\section{A. Latar belakang penelitian}

Setiap perusahaan selalu memerlukan persediaan dalam rangka menjaga kontinuitas produksi, tanpa adanya persediaan perusahaan akan dihadapkan pada resiko bahwa perusahaannya suatu waktu tidak dapat memenuhi keinginan konsumen (Rangkuti, 2007). Pada perusahaan yang bergerak dalam bidang distributor, persediaan menjadi salah satu komponen penting dalam kegiatan penjualan. Kegiatan penjualan perusahaan akan terus berlangsung selama perusahaan memiliki persediaan yang cukup. Terjadinya kekurangan persediaan selain dapat menghentikan kegiatan perusahaan juga dapat mengakibatkan 
konsumen untuk beralih mencari produk sejenis pada perusahaan lain, sehingga dapat mengurangi kesempatan perusahaan untuk memperoleh laba. Sebaliknya jika perusahaan memiliki persediaan yang cukup besar, perusahaan dapat memenuhi seluruh permintaan yang ada. Sedangkan persediaan yang terlalu besar (overstock) dapat melipatgandakan beban biaya persediaan selama penyimpanan di gudang.

PT. Wina Wira Usaha Jaya adalah perusahaan distributor yang bergerak dalam penyaluran bahan bakar gas atau LPG. Produk LPG yang dijual perusahaan berupa LPG dengan ukuran tabung subsidi $5 \mathrm{~kg}$, non subsidi $12 \mathrm{~kg}$ serta $50 \mathrm{~kg}$. PT. Wina Wira Usaha Jaya memiliki kelompok konsumen yang beragam mulai dari konsumen rumah tangga, retail, industri, bisnis, hingga peternakan dengan area jangkauan yang tersebar meliputi daerah Sleman, Bantul, sebagian kota Yogyakarta, serta sebagian daerah Kulon Progo.

PT. Wina Wira Usaha Jaya mengikuti aturan main dari Pertamina sebagai pemasok dalam pengadaan persediaannya. Setiap awal bulan pertamina memberikan kuota tabung LPG maksimal yang dapat diambil oleh perusahaan perbulan. Pertamina tidak memberikan batasan jumlah serta kapan distributor akan melakukan pemesanan selama tidak melebihi kuota per bulan yang telah ditetapkan. Tabung LPG baru dapat diambil setelah PT. Wina Wira Usaha Jaya melakukan penebusan pembayaran pesanan tabung LPG selambatlambatnya sehari sebelumnya. Setelah itu LPG dapat diambil di Stasiun Pengisian dan Pengangkutan Bulk Elpiji (SPPBE) yang telah ditunjuk.

Saat ini PT. Wina Wira Usaha Jaya belum memiliki jadwal pasti untuk penebusan tabung gas dan hanya melakukan penebusan tabung LPG perhari tergantung pada tabung kosong yang tersedia. Selain itu, Pertamina sebagai pemasok memberikan batasan penebusan khususnya untuk tabung gas ukuran $12 \mathrm{~kg}$ hanya bisa ditebus sebanyak 540 tabung perhari. Terbatasnya penebusan tabung LPG serta permintaan konsumen yang tidak pasti sering menyebabkan kurangnya ketersediaan tabung LPG di gudang. Kekurangan dari permintaan baru bisa dipenuhi pada periode pemesanan berikutnya yang mengakibatkan beberapa konsumen beralih kepada agen lain untuk memenuhi kebutuhannya, hal ini tentunya merupakan kerugian bagi perusahaan.

Berdasarkan permasalahan yang telah diuraikan diatas, penelitian di PT. Wina Wira Usaha Yogyakarta akan difokuskan pada sistem persediaan tabung gas LPG. Menurut Silver (1998) persediaan dengan permintaan yang probabilistik dapat dikelola dengan metode Periodic Review (Model P). Metode periodic review ini dapat digunakan untuk menentukan waktu periode pemesanan dan menentukan jumlah maksimal persediaan digudang

\section{B. Perumusan masalah}

Berdasarkan latar belakang maka rumusan masalah dalam penelitian ini adalah Bagaimana mengatur persediaan tabung gas yang ada di gudang agar selalu bisa memenuhi permintaan konsumen dengan biaya yang minimal.

\section{Batasan masalah}

Batasan masalah dalam penelitian ini adalah sebagai berikut :

1. Produk yang diteliti adalah tabung LPG ukuran $12 \mathrm{~kg}$ dan $50 \mathrm{~kg}$.

2. Data persediaan yang di gunakan adalah data perusahaan tahun 2014-2015. 


\section{Tujuan penelitian}

Tujuan dari penelitian ini adalah menentukan waktu periode pemesanan dan menentukan jumlah persediaan maksimal tabung gas yang ada di gudang.

\section{METODOLOGI PENELITIAN}

\section{A. Objek penelitian}

Obyek penelitian ini dilakukan di PT. Wina Wira Usaha Jaya yang beralamat di Jalan Kyai Mojo No.65, Tegalrejo, Kota Yogyakarta. Penelitian dilakukan pada produk tabung LPG ukuran $12 \mathrm{~kg}$ dan $50 \mathrm{~kg}$.

\section{B. Teknik pengumpulan data}

Untuk mendapatkan hasil yang memuaskan tentang gambaran suatu persoalan dalam suatu penelitian, diperlukan pengumpulan data-data. Berdasarkan macamnya data dibagi menjadi 2 yaitu:

1. Data primer

Data primer didapatkan peneliti melalui wawancara dengan pihak PT. Wina Wira Usaha Jaya

2. Data sekunder

Data-data sekunder yang digunakan dalam penelitian ini adalah:

a. Data permintaan tabung gas LPG dengan ukuran $12 \mathrm{~kg}$ dan $50 \mathrm{~kg}$ pada bulan Mei 2014 sampai dengan bulan Mei 2015.

b. Data harga pembelian tabung gas LPG ke supplier.

c. Biaya pemesanan per sekali pesan.

d. Biaya penyimpanan

\section{Kerangka penelitian}

Langkah-langkah penelitian ini dapat dilihat pada kerangka penelitian Gambar 1.1

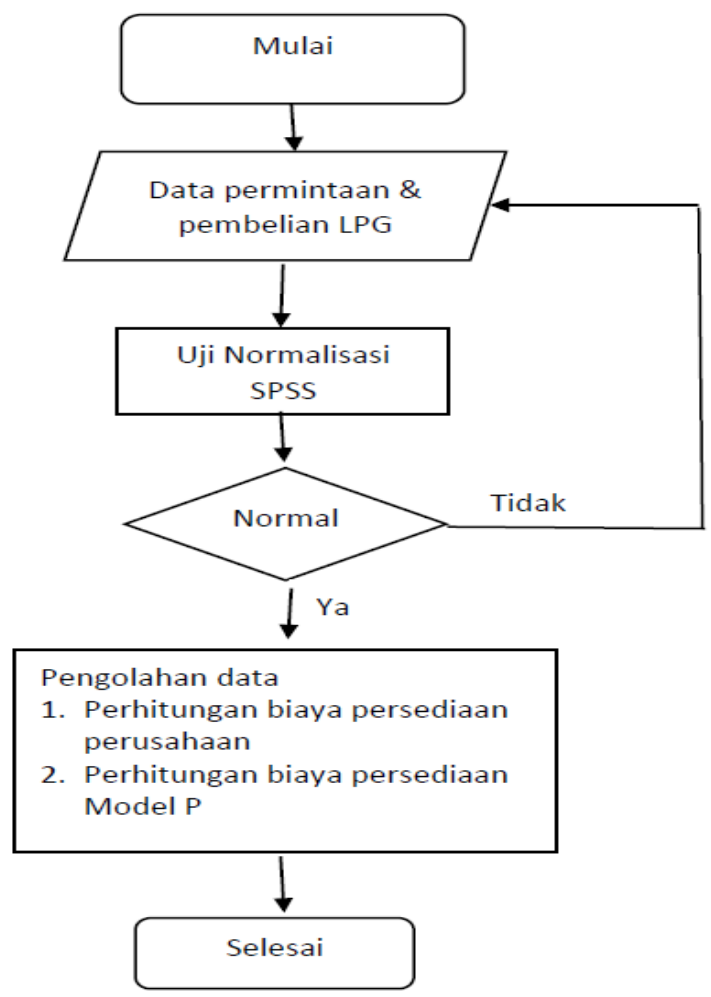

Gambar 1 Kerangka penelitian 


\section{ANALISA DAN PEMBAHASAN}

\section{A. Pengumpulan data}

1. Data permintaan

Data permintaan dan pembelian tabgng gas LPG bulan Mei 2014 sampai dengan bulan April 2015 adalah seprti dalam table 3.1

Tabel 1. Permintaan dan pembelian tabung Gas LPG bulan Mei 2014 sampai dengan bulan April 2015

\begin{tabular}{|c|c|c|c|c|c|}
\hline \multirow{2}{*}{$\begin{array}{c}\text { TAHU } \\
\mathbf{N}\end{array}$} & \multirow[b]{2}{*}{ BULAN } & \multicolumn{2}{|c|}{$\begin{array}{c}\text { PERMINTAAN } \\
\text { TABUNG GAS LPG }\end{array}$} & \multicolumn{2}{|c|}{$\begin{array}{c}\text { PEMBELIAN } \\
\text { TABUNG GAS LPG }\end{array}$} \\
\hline & & $\begin{array}{c}\text { Ukuran } 12 \\
\text { kg } \\
\text { (Tabung) }\end{array}$ & $\begin{array}{c}\text { Ukuran } 50 \\
\text { kg } \\
\text { (Tabung) }\end{array}$ & $\begin{array}{c}\text { Ukuran } 12 \\
\text { kg } \\
\text { (Tabung) }\end{array}$ & $\begin{array}{c}\text { Ukuran } 50 \\
\text { kg } \\
\text { (Tabung) }\end{array}$ \\
\hline \multirow{8}{*}{2014} & Mei & 14609 & 313 & 14371 & 260 \\
\hline & Juni & 14624 & 355 & 14551 & 370 \\
\hline & Juli & 15099 & 298 & 15377 & 310 \\
\hline & Agustus & 15388 & 344 & 15241 & 365 \\
\hline & $\begin{array}{l}\text { Septembe } \\
\mathrm{r}\end{array}$ & 13102 & 284 & 13481 & 265 \\
\hline & Oktober & 13927 & 352 & 13837 & 365 \\
\hline & November & 14762 & 324 & 14542 & 315 \\
\hline & Desember & 15554 & 344 & 15266 & 370 \\
\hline \multirow{4}{*}{2015} & Januari & 13285 & 245 & 13666 & 210 \\
\hline & Februari & 11705 & 185 & 11605 & 210 \\
\hline & Maret & 11716 & 242 & 11963 & 260 \\
\hline & April & 11397 & 273 & 10700 & 270 \\
\hline \multicolumn{2}{|c|}{ Jumlah } & 165168 & 3559 & 164600 & 3570 \\
\hline
\end{tabular}

\section{Data biaya persediaan}

Biaya-biaya yang berkaitan dengan persediaan di PT. Wina Wira Usaha Jaya, meliputi biaya pembelian, Biaya pemesanan, biaya penyimpanan dan biaya kekurangan persediaan . Adapun perincian biaya persediaan dapat di lihat pada tabel 3.2, tabel 3.3, tabel 3.4, dan tabel 3.5

Tabel 2 Biaya pembelian tabung gas LPG

\begin{tabular}{|c|c|}
\hline Jenis tabung & Harga beli \\
\hline Ukuran $12 \mathrm{~kg}$ & $\mathrm{Rp} 119.500,-$ \\
\hline Ukuran $50 \mathrm{~kg}$ & $\mathrm{Rp} 475.500,-$ \\
\hline
\end{tabular}

Tabel 3 Biaya pemesanan tabung gas LPG

\begin{tabular}{|c|c|c|c|}
\hline Jenis tabung & Biaya E-mail & $\begin{array}{c}\text { Biaya } \\
\text { Administrasi }\end{array}$ & TOTAL \\
\hline Ukuran 12 kg & $\operatorname{Rp~50,-}$ & $\operatorname{Rp~750,-}$ & $\operatorname{Rp~800,-~}$ \\
\hline Ukuran 50 kg & $\operatorname{Rp~50,-}$ & $\operatorname{Rp~750,-}$ & $\operatorname{Rp~800,-~}$ \\
\hline
\end{tabular}


Tabel 4 Biaya penyimpanan

\begin{tabular}{|c|c|c|c|}
\hline Jenis tabung & $\begin{array}{c}\text { Biaya simpan } \\
\text { gudang (2,5\%) }\end{array}$ & $\begin{array}{c}\text { Biaya Bongkar } \\
\text { Muat }\end{array}$ & TOTAL \\
\hline Ukuran $12 \mathrm{~kg}$ & $\mathrm{Rp} \mathrm{2.987,5}$ & $\mathrm{Rp} \mathrm{1.000,-}$ & $\mathrm{Rp} \mathrm{3.987,5}$ \\
\hline Ukuran 50 kg & $\mathrm{Rp} \mathrm{11.887,5}$ & $\mathrm{Rp} \mathrm{1.000,-}$ & $\mathrm{Rp} \mathrm{12.887,5}$ \\
\hline
\end{tabular}

Tabel 5 Biaya kekurangan persediaan

\begin{tabular}{|c|c|}
\hline Jenis tabung & $\begin{array}{c}\text { Biaya } \\
\text { Kekurangan } \\
(5 \%)\end{array}$ \\
\hline Ukuran $12 \mathrm{~kg}$ & $\mathrm{Rp} \mathrm{5.975,-}$ \\
\hline Ukuran $50 \mathrm{~kg}$ & $\operatorname{Rp} 23.775,-$ \\
\hline
\end{tabular}

\section{B. Pengolahan data}

\section{Uji normalisasi data menggunakan software SPSS}

Hasil uji normalisasi data menggunakan teknik Kolmogorov Smirnov dapat dilihat pada tabel 3.6 berikut :

Tabel 6 Hasil analisa normalitas SPSS

\section{Tests of Normality}

\begin{tabular}{|l|r|r|r|r|r|r|}
\hline & \multicolumn{3}{|c|}{ Kolmogorov-Smirnov $^{\mathrm{a}}$} & \multicolumn{3}{c|}{ Shapiro-Wilk } \\
\cline { 2 - 7 } & Statistic & \multicolumn{1}{c|}{ df } & \multicolumn{1}{c|}{ Sig. } & Statistic & \multicolumn{1}{c|}{ df } & \multicolumn{1}{c|}{ Sig. } \\
\hline DEMAND_12kg & .213 & 12 & .138 & .891 & 12 & .123 \\
DEMAND_50kg & .148 & 12 & $.200^{*}$ & .919 & 12 & .281 \\
BELI_12kg & .189 & 12 & $.200^{*}$ & .892 & 12 & .123 \\
BELI_50kg & .202 & 12 & .191 & .883 & 12 & .094 \\
\hline
\end{tabular}

Dari tabel di atas disimpulkan bahwa seluruh data yaitu data permintaan tabung gas ukuran $12 \mathrm{~kg}$ dan $50 \mathrm{~kg}$ serta data pembelian tabung gas ukuran $12 \mathrm{~kg}$ dan $50 \mathrm{~kg}$ berdistribusi normal dilihat dari nilai standar deviasi masing-masing data yang lebih besar dari 0,05 .

\section{Perhitungan biaya persediaan menggunakan kebijakan perusahaan}

Berdasarkan data perusahaan, biaya persediaan yang dikeluarkan perusahaan dapat dilihat pada table 7

Tabel 7 Hasil perhitungan biaya kebijakan perusahaan

\begin{tabular}{|l|r|r|r|r|}
\hline Biaya & $\begin{array}{l}\text { Tabung } \\
(\mathrm{Rp})\end{array}$ & \multicolumn{1}{|l|}{$\begin{array}{l}\text { Tabung } 50 \quad \mathrm{~kg} \\
(\mathrm{Rp})\end{array}$} & \multicolumn{1}{l|}{ Total (Rp) } \\
\hline Pembelian & $19.669 .100 .000,-$ & $1.697 .535 .000,-$ & $21.367 .235 .000,-$ \\
\hline Pemesanan & $420.800,-$ & $54.400,-$ & $475.200,-$ \\
\hline Penyimpanan & $656.342 .500,-$ & $46.008 .357,-$ & $702.350 .875,-$ \\
\hline $\begin{array}{l}\text { Kekurangan } \\
\text { persediaan }\end{array}$ & $84.050 .325,-$ & $2.020 .875,-$ & $86.071 .200,-$ \\
\hline \multicolumn{4}{|r|}{} \\
\hline
\end{tabular}

Total biaya persediaan yang dikeluarkan perusahaan selama setahun terhitung bulan Mei 2014 sampai dengan bulan April 2015 sesuai data perusahaan adalah sebesar Rp 22.156.132.275,- 


\section{Perhitungan biaya persediaan menggunakan model periodic review ( $\mathbf{P}$ )}

Hasil perhitungan standar deviasi untuk tabung $12 \mathrm{~kg}$ dan tabung gas $50 \mathrm{~kg}$ dapat dilihat pada Tabel 8 .

Tabel 8 Hasil perhitungan standar deviasi tabung LPG $12 \mathrm{~kg}$ dan tabung gas $50 \mathrm{~kg}$

\begin{tabular}{|r|l|c|r|c|r|}
\hline & & \multicolumn{2}{|c|}{ Tabung $12 \mathrm{Kg}$} & \multicolumn{2}{c|}{ Tabung 50 kg } \\
\hline $\begin{array}{c}\text { Peri } \\
\text { ode }\end{array}$ & Bulan & $\begin{array}{c}\text { Permintaan } \\
\text { (Tabung gas) }\end{array}$ & $\left(\boldsymbol{X}_{\boldsymbol{i}}-\overline{\boldsymbol{X}}\right)^{2}$ & $\begin{array}{c}\text { Permintaan } \\
\text { (tabung gas })\end{array}$ & $\left(\boldsymbol{X}_{\boldsymbol{i}}-\overline{\boldsymbol{X}}\right)^{2}$ \\
\hline 1 & Mei & 14.609 & $714.025,00$ & 313 & 269,51 \\
\hline 2 & Juni & 14.624 & $739.600,00$ & 355 & 3412,51 \\
\hline 3 & Juli & 15.099 & $1.782 .225,00$ & 298 & 2,01 \\
\hline 4 & Agustus & 15.388 & $2.637 .376,00$ & 344 & 2248,34 \\
\hline 5 & September & 13.102 & $438.244,00$ & 284 & 158,34 \\
\hline 6 & Oktober & 13.927 & $26.569,00$ & 352 & 3071,01 \\
\hline 7 & November & 14.762 & $996.004,00$ & 324 & 751,67 \\
\hline 8 & Desember & 15.554 & $3.204 .100,00$ & 344 & 2248,34 \\
\hline 9 & Januari & 13.285 & $189.447 .696,00$ & 245 & 87961,67 \\
\hline 10 & Februari & 11.705 & $229.441,00$ & 185 & 2660,84 \\
\hline 11 & Maret & 11.716 & $4.239 .481,00$ & 242 & 12450,84 \\
\hline 12 & April & 11.397 & $4.194 .304,00$ & 273 & 2979,34 \\
\hline \multicolumn{2}{|c|}{ Jumlah } & $\mathbf{1 6 5 . 1 6 8}$ & & $\mathbf{3 . 5 5 9}$ & \\
\hline \multicolumn{2}{|c|}{ Rata-rata } & $\mathbf{1 . 3 7 6 4 , 0 0}$ & & $\mathbf{2 9 6 , 5 8}$ & \\
\hline
\end{tabular}

Proses perhitungan selanjutnya menentukan total ongkos persediaan yang optimal dengan metode Hadley-Within dengan kasus lost sales melalui proses iterasi. Berikut contoh perhitungan iterasi yang dilakukan pada tabung ukuran $12 \mathrm{~kg}$ yang ada:

Iterasi 1

a. Mengitung nilai periode antar pemesanan $\mathrm{T}_{0}$ :

$$
T_{o}=\sqrt{\frac{2 A}{D h}}=0,0022
$$

b. Menghitung kemungkinan terjadinya kekurangan persediaan $(\alpha)$ :

$$
\alpha=\frac{h \cdot T}{h \cdot T+c_{u}}=0,0015
$$

c. Menghitung nilai R :

Berdasarkan tabel distribusi normal standar (Bahagia, 2006) dengan nilai $\alpha$ $=0,0015$ diperoleh $\mathrm{z}_{\alpha}=3,00$

$R=D T+D_{L}+z_{\alpha} \sqrt{T+L}=816,80 \approx 817$

d. Menghitung total ongkos persediaan $\mathrm{O}_{\mathrm{T}}$

$$
O_{T}=D p+\frac{A}{T}+h\left(R-D_{L}+\frac{D T}{2}\right)+\left(\frac{c_{u}}{T}+h\right) \int_{R}^{\infty}(z-R) f(z) d z=\mathrm{Rp}
$$

19.743.195.777,- 
Iterasi 2

a. Disini iterasi dicoba dengan penambahan $\mathrm{T} 0$ sebesar 0,0027 tahun sehingga $\mathrm{T}_{0}=$ 0,0049 kemudian kembali ke langkah 2.

b. Menghitung kemungkinan terjadinya kekurangan persediaan $(\alpha)$ :

$$
\alpha=\frac{h \cdot T}{h \cdot T+c_{u}}=0,0033
$$

c. Menghitung nilai $\mathrm{R}$ :

Berdasarkan tabel distribusi normal standar (Bahagia, 2006) dengan nilai $\alpha$ $=0,0033$ diperoleh $\mathrm{z}_{\alpha}=2,72$

$$
R=D T+D_{L}+z_{\alpha} \sqrt{T+L}=1262,78 \approx 1263
$$

d. Menghitung total ongkos persediaan $\mathrm{O}_{\mathrm{T}}$

$$
O_{T}=D p+\frac{A}{T}+h\left(R-D_{L}+\frac{D T}{2}\right)+\left(\frac{c_{u}}{T}+h\right) \int_{R}^{\infty}(z-R) f(z) d z=
$$

RP 19.746.415.998,-

\section{Iterasi 3}

a. Karena hasil total biaya persediaan iterasi 2 lebih besar maka iterasi penambahan dihentikan dan dilanjutkan dengan iterasi pengurangan T0 sebesar 0,0015 tahun sehingga $\mathrm{T} 0=0,0007$ kemudian kembali ke langkah 2 .

b. Menghitung kemungkinan terjadinya kekurangan persediaan $(\alpha)$ :

$$
\alpha=\frac{h \cdot T}{h \cdot T+c_{u}}=0,0005
$$

c. Menghitung nilai $\mathrm{R}$ :

Berdasarkan tabel distribusi normal standar (Bahagia, 2006) dengan nilai $\alpha$ $=0,0005$ diperoleh $\mathrm{z}_{\alpha}=3,30$

$R=D T+D_{L}+z_{\alpha} \sqrt{T+L}=569,03 \approx 570$

d. Menghitung total ongkos persediaan $\mathrm{O}_{\mathrm{T}}$

$$
O_{T}=D p+\frac{A}{T}+h\left(R-D_{L}+\frac{D T}{2}\right)+\left(\frac{c_{u}}{T}+h\right) \int_{R}^{\infty}(z-R) f(z) d z=\mathrm{Rp}
$$

19.749.036.431,-

Karena total ongkos persediaan yang didapat lebih besar, maka iterasi dihentikan dan tidak dilanjutkan. Selanjutnya dilakukan perhitungan untuk tabung gas ukuran $50 \mathrm{~kg}$ dengan cara yang sama seperti diatas. Hasil iterasi pada tabung gas ukuran $12 \mathrm{~kg}$ dan 50 kg selengkapnya dapat dilihat pada tabel 3.9

Tabel 3.9 Hasil periode pesan dan jumlah persediaan opimum berdasarkan hasil Iterasi

\begin{tabular}{|c|c|c|c|c|c|l|}
\hline $\begin{array}{c}\text { Jenis } \\
\text { Tabung }\end{array}$ & $\begin{array}{c}\text { Iterasi } \\
\text { ke }\end{array}$ & $\begin{array}{c}\mathbf{T} \\
\text { (tahun) }\end{array}$ & $\begin{array}{c}\mathbf{R} \\
\text { (Tabung) }\end{array}$ & $\begin{array}{c}\mathbf{N} \\
\text { (Tabung) }\end{array}$ & $\begin{array}{c}\text { OT } \\
\text { (Rp) }\end{array}$ & Keterangan \\
\hline \multirow{2}{*}{$\begin{array}{c}\text { Ukuran } \\
12 \mathrm{~kg}\end{array}$} & 1 & 0,0022 & 817 & 1 & 19.743 .195 .777 & OPTIMAL \\
\cline { 2 - 7 } & 2 & 0,0049 & 1263 & 3 & 19.746 .415 .998 & \\
\cline { 2 - 7 } & 3 & 0,0007 & 570 & 1 & 19.749 .036 .431 & \\
\hline
\end{tabular}




\begin{tabular}{|c|c|c|c|c|c|c|} 
& 1 & 0,0084 & 40 & 1 & 1.695 .936 .722 & \\
\cline { 2 - 7 } & 2 & 0,0111 & 50 & 1 & 1.695 .385 .395 & \\
\cline { 2 - 7 } Ukuran & 3 & 0,0138 & 60 & 1 & 1.695 .125 .463 & \\
\cline { 2 - 7 } $50 \mathrm{~kg}$ & 4 & 0,0165 & 69 & 1 & 1.695 .000 .578 & \\
\cline { 2 - 7 } & 5 & 0,0192 & 79 & 1 & 1.694 .973 .951 & OPTIMAL \\
\cline { 2 - 7 } & 6 & 0,0219 & 88 & 1 & 1.694 .988 .164 & \\
\hline
\end{tabular}

Dari hasil perhitungan diperoleh kebijakan optimal sebagai berikut:

1. Periode antar pemesanan optimal $\mathrm{T}^{*}$ masing-masing :

- Tabung gas ukuran $12 \mathrm{~kg} \mathrm{T1} *=0,0022$ tahun

- Tabung gas ukuran $50 \mathrm{~kg} \mathrm{~T} 2 *=0,0192$ tahun

2. Nilai inventori maksimal $\mathrm{R}^{*}$ untuk masing-masing ukuran tabung gas :

- Tabung gas ukuran $12 \mathrm{~kg} \mathrm{R} 1 *=817$ tabung

- Tabung gas ukuran $50 \mathrm{~kg} \mathrm{R} 2 *=79$ tabung

3. Total biaya persediaan yang dikeluarkan menjadi :

OT $=$ Rp 19.743.195.777,- + Rp 1.694.973.951,- = Rp 21.438.169.728,-

Perbandingan biaya persediaan antara system persediaan yang dilakukan oleh perusahaan dengan system persediaan menggunakan model periodic review dapat dilihat pada tabel 3.10

Tabel 3.10 Perbandingan biaya persediaan antara yang dilakukan perusahaan dengan perhitungan biaya persediaan menggunakan model $\mathrm{P}$

\begin{tabular}{|c|c|c|c|c|c|}
\hline $\begin{array}{c}\text { Jenis } \\
\text { tabung }\end{array}$ & $\begin{array}{c}\mathrm{T} \\
\text { (tahun) }\end{array}$ & $\begin{array}{c}\text { R } \\
\text { (Tabung) }\end{array}$ & $\begin{array}{c}\mathrm{N} \\
\text { (Tabung) }\end{array}$ & $\begin{array}{c}\text { OT } \\
(\mathbf{R p})\end{array}$ & $\begin{array}{l}\text { TOTAL } \\
\text { (Rp) }\end{array}$ \\
\hline \multicolumn{5}{|c|}{ Hasil perusahaan } & 22.156.132.275 \\
\hline \multicolumn{6}{|c|}{ Periodic Review System (Model P) } \\
\hline $12 \mathrm{~kg}$ & 0,0022 & $\begin{array}{c}817 \\
\text { tabung }\end{array}$ & $\begin{array}{l}\mathrm{N} 1=1 \\
\text { tabung }\end{array}$ & 19.743.195.777 & \multirow{3}{*}{$\begin{array}{c}\mathrm{Rp} \\
21.438 .169 .728\end{array}$} \\
\hline $50 \mathrm{~kg}$ & 0,0192 & 79 tabung & $\begin{array}{l}\mathrm{N} 2=1 \\
\text { tabung }\end{array}$ & 1.694.973.951 & \\
\hline $50 \mathrm{~kg}$ & 0,0192 & 79 tabung & $\begin{array}{l}\mathrm{N} 2=1 \\
\text { tabung }\end{array}$ & 1.694.973.951 & \\
\hline
\end{tabular}

\section{Analisis hasil}

Berdasarkan hasil analisa normalitas dengan bantuan software SPSS menggunakan Uji Kolmogorov - Smirnov yang dapat dilihat pada Tabel 4.2 diketahui sebagai berikut: data permintaan tabung gas ukuran $12 \mathrm{~kg}$ memiliki nilai standar deviasi sebesar 0,138 , data permintaan tabung gas ukuran $50 \mathrm{~kg}$ memiliki nilai standar deviasi sebesar 0,200 , data pembelian tabung gas $12 \mathrm{~kg}$ perusahaan memiliki nilai standar deviasi 0,200 , serta data pembelian tabung gas $50 \mathrm{~kg}$ perusahaan memiliki nilai standar deviasi 0,191 . Nilai standar deviasi dari keseluruhan data lebih besar dari 0,05 sehingga dapat disimpulkan bahwa seluruh data diambil dari populasi yang berdistribusi normal.

Berdasarkan data pembelian yang diperoleh dari data perusahaan didapati bahwa total biaya persediaan yang dikeluarkan perusahaan selama setahun terhitung dari bulan Mei 2014 hingga April 2015 adalah sebesar Rp22.156.132.275,-. Perusahaan memiliki 
jumlah tabung maksimal untuk ukuran $12 \mathrm{~kg}$ sebanyak 1.380 tabung serta untuk ukuran 50 kg sebanyak 150 tabung.

Berdasarkan hasil perhitungan iterasi yang terangkum dalam Tabel 4.6 didapati kebijakan persediaan yang optimal dengan total biaya persediaan yang dikeluarkan pertahun sebesar OT $=$ Rp 21.438.169.728,- dengan interval waktu antar pemesanan masing-masing sebesar $\mathrm{T}^{*}=0,0022$ tahun (19 jam 18 menit) untuk tabung gas ukuran 12 $\mathrm{kg}$ serta $\mathrm{T}^{*}=0,0192$ tahun (6 hari 23 jam 46 menit) untuk tabung gas berukuran $50 \mathrm{~kg}$. Inventori maksimal yang optimal untuk tiap tabung gas masing-masing sebanyak 817 tabung untuk tabung gas ukuran $12 \mathrm{~kg}$ dan sebanyak 79 tabung untuk tabung gas ukuran 50 $\mathrm{kg}$.

Berdasarkan hasil perhitungan didapakan bahwa biaya persediaan dengan Model $P$ lebih rendah bila dibandingkan dengan biaya persediaan yang dilakukan oleh perusahaan saat ini. Adapun selisih biaya adalah sebesar Rp 717.962.547,-

\section{KESIMPULAN}

Berdasarkan dari hasil pengolahan data dapat disimpulkan bahwa dengan menggunakan model periodic review didapatkan biaya persediaan yang lebih minimal, . yaitu bisa menurunkan biaya persediaan sebesar 3,24 \%. dari kebijakan perusahaan sebelumnya.

\section{DAFTAR PUSTAKA}

Bahagia, S.N., 2006, Sistem Inventori, Bandung; Penerbit ITB.

Nasution, A. H., dan Prasetyawan, Y., 2008, Perencanaan dan Pengendalian Produksi, Edisi Pertama, Graha Ilmu, Yogyakarta.

Mardani M.M., 2001, Petunjuk Praktis SPSS 10.0, Badan Penerbit Fakultas Ekonomi Universitas Islam, Malang

Penangsang, W. A. S., 2010, Pengendalian Persediaan Spare Part dengan Pendekatan Periodic Review $(R, s, S)$ System, Jurnal TI ITS, Surabaya

Rangkuti, F., 2007, Manajemen Persedian Aplikasi di Bidang Bisnis; PT. Raja Grafindo Persada, Jakarta.

Silver, E. A., Pyke, David, F., Peterson, Rein, 1998, Inventory Management and Production Planning and Scheduling, John Wiley \& Sons, New York.

Tersine, Richard J., 1994, Inventory and Material Management, $3^{\text {rd }}$ Edition, Elsevier Publishing, USA.

Yamit, Z., 2003, Manajemen Persediaan, Yogyakarta; Ekonisia Fakultas Ekonomi UII. 